\title{
Establishing Normative Data on Singing Voice Parameters of Children and Adolescents with Average Singing Activity Using the Voice Range Profile
}

\author{
Tobias Dienerowitz $^{\mathrm{a}, \mathrm{c}}$ Thomas Peschel ${ }^{c}$ Mandy Vogel ${ }^{c}$ Tanja Poulain $^{c}$ \\ Christoph Engel $^{b, c}$ Wieland Kiess ${ }^{c, d}$ Michael Fuchs ${ }^{a, c}$ Thomas Berger ${ }^{a, c}$
}

aSection of Phoniatrics and Audiology, Department of Otorhinolaryngology, University of Leipzig, Leipzig,

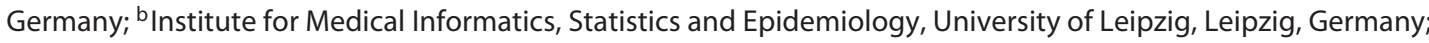
'LIFE Leipzig Research Center for Civilization Diseases, University of Leipzig, Leipzig, Germany; ${ }^{\mathrm{d}}$ Department of Women and Child Health, Hospital for Children and Adolescents and Center for Pediatric Research (CPL), University of Leipzig, Leipzig, Germany

\section{Keywords}

Singing voice $\cdot$ Voice range profile $\cdot$ Normative data .

Maximum fundamental frequency · Minimum fundamental frequency · Sound pressure level - Maximum phonation time

\footnotetext{
Abstract

Purpose: The purpose of this study was to establish and characterize age- and gender-specific normative data of the singing voice using the voice range profile for clinical diagnostics. Furthermore, associations between the singing voice and the socioeconomic status were examined. Methods: Singing voice profiles of 1,578 mostly untrained children aged between 7.0 and 16.11 years were analyzed. Participants had to reproduce sung tones at defined pitches, resulting in maximum and minimum fundamental frequency and sound pressure level (SPL). In addition, maximum phonation time (MPT) was measured. Percentile curves of frequency, SPL and MPT were estimated. To examine the associations of socioeconomic status, multivariate analyses
}

adjusted for age and sex were performed. Results: In boys, the mean of the highest frequency was $750.9 \mathrm{~Hz}$ and lowered to $397.1 \mathrm{~Hz}$ with increasing age. Similarly, the minimum frequency was $194.4 \mathrm{~Hz}$ and lowered to $91.9 \mathrm{~Hz}$. In girls, the mean maximum frequency decreased from 754.9 to 725.3 $\mathrm{Hz}$. The mean minimum frequency lowered from 202.4 to $175.0 \mathrm{~Hz}$. For both sexes, the mean frequency range $\Delta \mathrm{f}$ showed a constant range of roughly 24 semitones. The MPT increased with age, for boys and girls. There was neither an effect of age nor sex on $\mathrm{SPL}_{\text {min }}$ or $\mathrm{SPL}_{\text {max }}$, ranging between 52.6 and $54.1 \mathrm{dBA}$ and between 86.5 and $82.8 \mathrm{dBA}$, respectively. Socioeconomic status was not associated with the above-mentioned variables. Conclusion: To our knowledge, this study is the first to present large normative data on the singing voice in childhood and adolescence based on a high number of measurements. In addition, we provide percentile curves for practical application in clinic and vocal pedagogy which may be applied to distinguish between normal and pathological singing voice.

(C) 2021 The Author(s)

Published by S. Karger AG, Basel
(C) 2021 The Author(s)

Published by S. Karger AG, Basel

This is an Open Access article licensed under the Creative Commons Attribution-NonCommercial-4.0 International License (CC BY-NC) (http://www.karger.com/Services/OpenAccessLicense), applicable to the online version of the article only. Usage and distribution for commercial purposes requires written permission.
Tobias Dienerowitz

Department of Cardiology at Heidelberg University Hospital Im Neuenheimer Feld 410

DE-69120 Heidelberg (Germany)

t.dienerowitz@gmail.com 


\section{Introduction}

The voice is an integral part of communication, enabling social interaction in adults and children alike. During childhood and adolescence, processes like growth, maturation, and puberty have an important influence on the development of a child's voice. Vocal disorders during that time can have a severe impact on a child's social behavior and academic achievement, possibly leading to higher unemployment rates in later life [1-3]. Those ailments are not rare as prevalence in children is estimated at $6 \%$ [4], other studies even stating a percentage as high as $24 \%$, especially in urban areas $[5,6]$. These vocal illnesses may present themselves as throat clearing or coughing, the voice becomes strained or tires, the voice gets low or hoarse, difficulty in being heard, sensation of tension, pain, or lump in the throat, and voice breaks while talking. The most common manifestation in childhood is a hyperfunctional voice disorder with vocal nodules as secondary organic changes of the epithelium $[6,7]$. Therefore, detecting these illnesses should be a focus of phoniatricians and pediatricians.

Previously, study populations were mostly too small to derive normative data, some consider exclusively vocally trained or untrained children or specific age groups like infants or boys during voice change $[2,8,9]$. Due to the lack of normative data, the interpretation of the singing voice remains subjective. This study aimed to establish normative data on the singing voice of mostly untrained children and adolescents, who represent a typical distribution of singing activity in a normal population. Due to an exceptionally high number of 1,578 of participants, solid normative data could be created.

The voice range profile (VRP) is a common diagnostic tool to qualify and quantify basic parameters of the singing and speaking voice. Titze [10] described it as a standard nonspeech task for the assessment of laryngeal motor control to assess the pitch and the loudness. Being a noninvasive, semiobjective tool, it is useful to visualize the extent of the frequencies someone may produce sung at low intensity and high intensity, thus showing the dimension of the vocal frequency and intensity. It might assist the diagnosis of voice problems. Accordingly, irregular findings might indicate voice disorders like hoarseness, glottal chinks, and nodules or functional misuse of the voice $[11,12]$.

As this study aims to provide normative data, percentile curves have been estimated as well. Percentile curves are commonly used in pediatrics to visualize the age-varying distribution of a parameter. Therefore, the method facilitates the assessment of an individual's performance in the context of the sex- and age-adjusted norm.

In addition to frequency and intensity ranges this study establishes normative data on the maximum phonation time (MPT) which is used as an indicator of phonatory control [13]. Furthermore, a reduction of MPT is a measure of voice impairments according to the International Classification of Functioning, Disability and Health. Hillel et al. [14] suggest that any shortening of the MPT indicates potential vocal disabilities, like vocal nodules, chronic laryngitis vocal polyps, and others [15]; therefore, it can be used to assess an individual's voice health status [16].

Besides the general description of the voice profile, the relationship between socioeconomic status and children's voice was assessed. So far, only a few studies have investigated possible associations even though social background plays an important role in health. In lower-income families deficient communication culture due to the lack of a framework for objective argumentation, or patient listening, as well as high noise level in the family environment, is more common [17]. This might lead to long-term overstraining of vocal capabilities and thus to the development of vocal disorders [18]. These traits might also be found in larger families, disregarding their social status. Moreover, associations between a child's speaking-voice intensity and the personality, especially extraversion and emotional stability, which are more common in families with higher socioeconomic background, were described by Poulain et al. [19]. Smillie et al. [20] state that socioeconomic status has an impact on the children's speaking voice, with children from lower social backgrounds showing more vocal disorders. Therefore, this study tries to show whether socioeconomic status has an influence on the singing voice.

\section{Materials and Methods}

\section{Study Population}

This study is part of the LIFE Child Study, an ongoing large prospective cohort study, which started in 2011 (clinical trial No. NCT02550236) [21, 22]. The LIFE Child Study has been designed to understand how (epi)genetic, metabolic, and environmental factors influence health and development in children and adolescents in modern society. More than 4,000 children, adolescents, and their families have been recruited so far. The VRP examinations were conducted to gain information on the natural development and variation of voice parameters during childhood and adolescence. The term adolescence used in this study describes par- 
ticipants at the beginning of puberty up to the age of majority of 18 years, as in most countries. Between 2011 and 2016 one VRP measurement of each of the 1,578 children aged between 7.0 and 16.11 years was collected. 91 measurements had to be excluded as described below. Thus, the analyses are based on a total of 1,487 measurements.

\section{Voice Measurement}

The VRP included speaking voice as well as singing voice tasks. The speaking voice of the participants was analyzed by Berger et al. [23] and will not be a part of this study. The singing voice was assessed with frequency and intensity parameters while reproducing defined pitches presented by the examiner using an electric piano, thus we describe a specific function or phonatory capabilities of the larynx. The sequence of tones started at a pitch in the middle of the speaking voice range of each subject lowering down to a minimum and advancing subsequently to higher frequencies until a maximum was reached. First, the subject was asked to sing as softly as possible, afterward as loudly as possible. If a participant was able to use the high register, this was included in the measurement. Throughout the recording, the investigators provided the subjects with hand signals to coach them for further lowering/increasing their volume. The examiner was allowed to give instructions and advice even during the recording, as deemed necessary. In case of software malfunction or vocal failure, the examiner could delete the respective recording and start a second attempt. The VRP visualizes each frequency and their correspondent intensities.

In addition, the subject was instructed to hold a sung tone for as long as possible within a comfortable pitch and loudness quantifying the MPT. To exclude any training effect of the MPT, this procedure was only done once.

All examiners had been trained and certified by phoniatricians. Furthermore, to ensure high quality over the entire study period and to increase examiner reliability, they were periodically (every 3 months) full-time recertified and supervised by the above-mentioned specialists. To reduce external noise all measurements were performed in a soundproof room. Ambient noise did not exceed $40 \mathrm{~dB}$ according to the standard operating procedures recommended by the Union of the European Phoniatricians [24]. Singing voices were recorded using DiVAS ${ }^{\circledR}$ software (XION Medical, Berlin, Germany) running on a portable Windows-based PC. It includes a self-calibrating XION USB-microphone-headset with a constant distance of $30 \mathrm{~cm}$ from the subject's mouth, which secures the exact measurement of the parameters, without prior calibration. Unlike adults, who are supposed to stand at a defined spot, the participant could rest on his parent's lap in order to reduce timidity or movements during the examination. Those comprehensive standard operating procedures ensure a high and stable quality of the registration of the voice parameters.

In this study, the highest and lowest fundamental frequency $\left(\mathrm{f}_{0 \max }[\mathrm{Hz}], \mathrm{f}_{0 \min }[\mathrm{Hz}]\right)$ were taken into account. The difference between both, $\Delta \mathrm{f}$ [semitones] $\left(\mathrm{f}_{0 \max }-\mathrm{f}_{0 \min }\right)$, that is, the frequency range of an individual, was expressed in semitones using the scientific pitch notation $\left(\mathrm{A} 0=\mathrm{a}^{\prime}=440 \mathrm{~Hz}\right)$ to allow a straightforward comparison. Furthermore, the sound pressure level (SPL $[\mathrm{dBA}]$ ), was expressed by the loudest $\left(\mathrm{SPL}_{\max }\right)$ and the softest $\left(\mathrm{SPL}_{\min }\right)$ tone sung by each participant, and their margin $\triangle$ SPL was described. Finally, the MPT (s) was assessed.

Normative Data on Singing Voice

Parameters Using the Voice Range Profile

\section{Exclusion Criteria}

To ensure a high data quality 91 measurements had to be excluded. To obtain reliable and analyzable data on a singing voice $>4$ tones sung softly and another 4 sung loudly needed to be accurately recorded for each child. All measurements were assessed individually, not only visually, but also audibly. In the course of this the accuracy of the pitch-matching was assessed. 72 measurements did not meet the prerequisites. In addition, 12 children were not vocally healthy at the day of examination, having an upper respiratory infection or were hoarse. 7 measurements had to be removed due to technical problems. Hence of the total of 1,578 measurements, 1,487 could be evaluated.

\section{Sociodemographics and Singing Activity}

To determine the socioeconomic status of each participant the adjusted Winkler index was applied, taking into account education and occupational status of the parents as well as the equivalent household income. The resulting score can be classified into upper, middle, and lower class $[25,26]$. The children, if needed with the help of their parents, were asked via a standardized questionnaire following the classification by Fuchs et al. [27] about their degree of vocal strain and vocal training and whether they played a wind instrument, as there are indications in the literature that this may lead to increased strain on the vocal apparatus. Based on the classification of singing activity defined by Fuchs et al. [27], the study population showed that $90.8 \%$ of the participating children had no voice training, and sing only spontaneously and not in front of an audience. $9.2 \%$ of the children engage in occasional or regular organized singing and have voice training in a large group up to individual lessons. All children were included while estimating reference percentiles because this composition is typical for a western population.

\section{Statistical Analyses}

Statistical analyses were conducted using $R$ for Macintosh version 3.4.1 (RStudio Inc., Boston, MA, USA). Linear regression and multiple linear regression models were used to analyze the association of age, sex, and socioeconomic status as independent variables. $p$ values $\leq 0.05$ were considered to be statistically significant. To estimate percentile curves of the voice frequency an LMS-type method implemented as a generalized additive model for location, scale, and shape was applied (GAMLSS). The method is recommended by the World Health Organization for generating agedependent reference values. It was used in the World Health Organization multicenter growth study to establish the new international growth standard [28, 29].

\section{Ethics}

The study was designed in accordance with the Declaration of Helsinki and under the supervision of the Ethics Committee of the University of Leipzig (Reg. No. 264-10-19042010). Each participant and the authorized representative were informed about the study program, the long-term use of data, potential risks of participation, and the right to withdraw from the study. Informed written consent was provided by all parents and, from the age of 12 years, by the children themselves.
Folia Phoniatr Logop 2021;73:565-576

DOI: $10.1159 / 000513521$ 
Table 1. Voice characteristics of the study population stratified by age

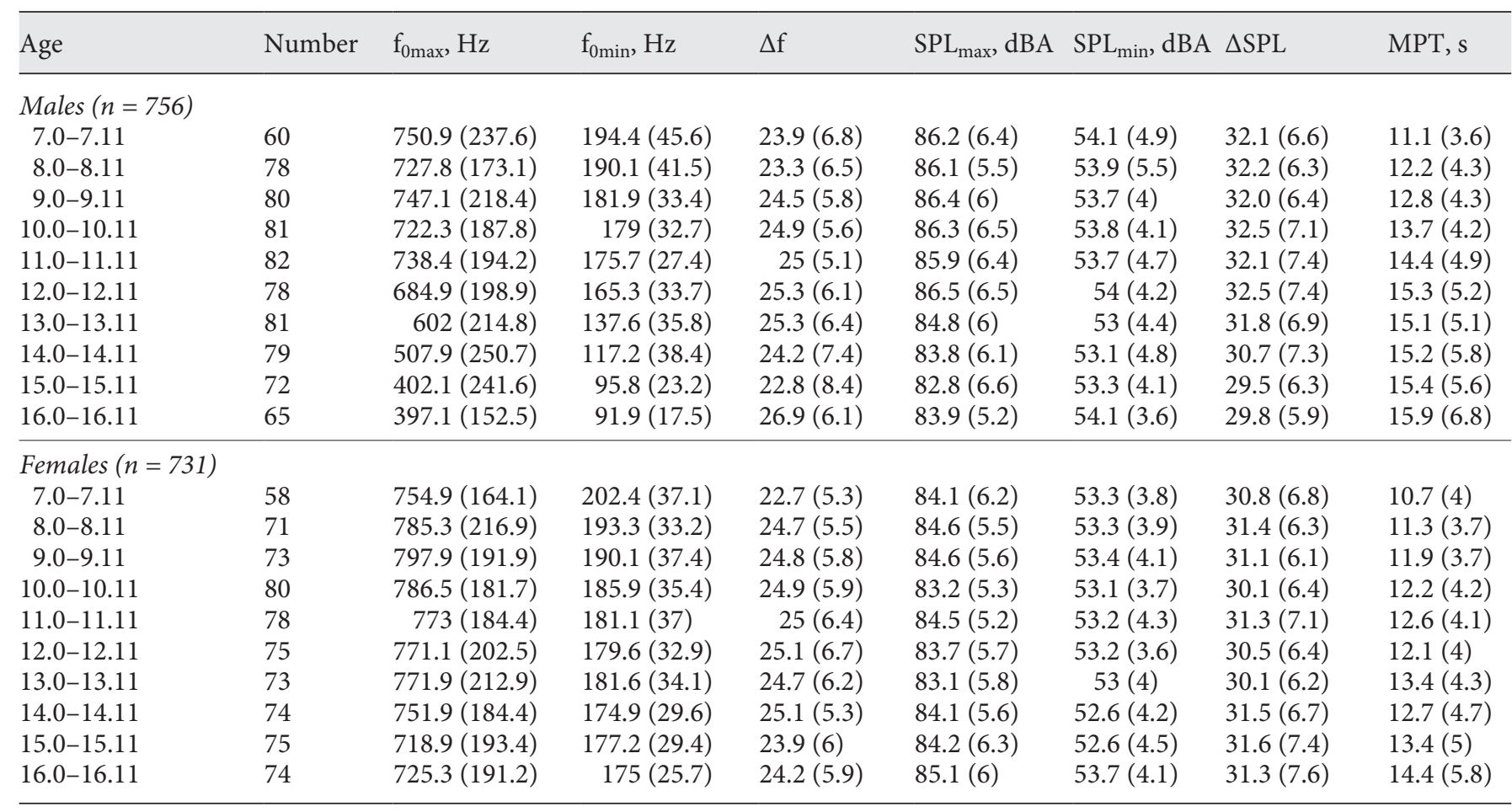

Ages are expressed in years and months. $\mathrm{f}_{0 \max }$ and $\mathrm{f}_{0 \mathrm{~min}}$, minimum and maximum fundamental frequency; $\Delta \mathrm{f}$, difference of frequency; $\mathrm{SPL}_{\max }$ and $\mathrm{SPL}_{\min }$, maximum and minimum sound pressure level; $\triangle \mathrm{SPL}$, difference of sound pressure level; MPT, maximum phonation time.

\section{Results}

\section{Data Summary}

In summary 1,487 measurements were considered. Of those 756 (50.8\%) were male and 731 (49.2\%) female. Table 1 shows the voice characteristics of the study population stratified by age.

\section{Frequency: Effects of Age and Sex}

The mean highest fundamental frequency for males as well as the mean lowest fundamental frequency of male singing voices did not change significantly up to the age of $12\left(p \leq 0.05, f^{2}=0.32\right)$. During voice change, it lowered significantly until the mean lowest and highest frequencies reach a stable level at the age of 15 . The largest slope might be seen for males during the voice change between 12 and 15 years of age where the maximum frequency decreased by $117.6 \mathrm{~Hz}\left(95 \%\right.$ CI 145.0-90.2; $p \leq 0.05, f^{2}=$ 0.45 ); at 12 it was $684.9 \mathrm{~Hz}$ and at 15 years $402.1 \mathrm{~Hz}$. In males the mean highest frequency lowered from $750.9 \mathrm{~Hz}$ (corresponding roughly to $\mathrm{G}_{5}$ ) at the age of 7 to $397.1 \mathrm{~Hz}$ $\left(\mathrm{G}_{4}\right)$ at the age of 16 years $(p \leq 0.05, d=0.74)$. Similarly the minimum frequency lowered from $194.4 \mathrm{~Hz}\left(\mathrm{G}_{3}\right)$ at the age of 7 to $91.9 \mathrm{~Hz}\left(\mathrm{~Gb}_{2}\right)$ at the age of $16(p \leq 0.05$, $d=0.63$ ). Thus, male voices lower by around one octave during voice change.

The mean highest fundamental frequency of female singing voices changed significantly with increasing age. It shows, in contrast to male singing voices, a linear lowering of $8.2 \mathrm{~Hz}$ (95\% CI 11.9-4.6) per year $\left(p \leq 0.05, f^{2}=\right.$ 0.152 ). Likewise, the mean lowest fundamental frequency of female singing voices lowered $3.0 \mathrm{~Hz}$ (95\% CI 3.6-2.4) per year $\left(p \leq 0.05, f^{2}=0.143\right)$. In females the mean maximum frequency also lowers continuously and significantly, but not starkly, from $754.9\left(\mathrm{G}_{5}\right)$ at the age of 7 to 725.3 $\left(\mathrm{F}_{5}\right)$ at the age of 16 years $(p \leq 0.05, d=0.53)$. A similar trend can be observed for the minimum frequency from $202.4 \mathrm{~Hz}\left(\mathrm{Ab}_{3}\right)$ at the age of 7 to $175.0 \mathrm{~Hz}\left(\mathrm{~F}_{3}\right)$ at the age of 16 years. Female voices lower approximately 2 semitones per year during adolescence.

Figure 1 shows the percentile curves for $\mathrm{f}_{0 \max }$ and $\mathrm{f}_{0 \min }$ in males and females. Note the decrease of the margin for frequency at the age of 12 years for males. 

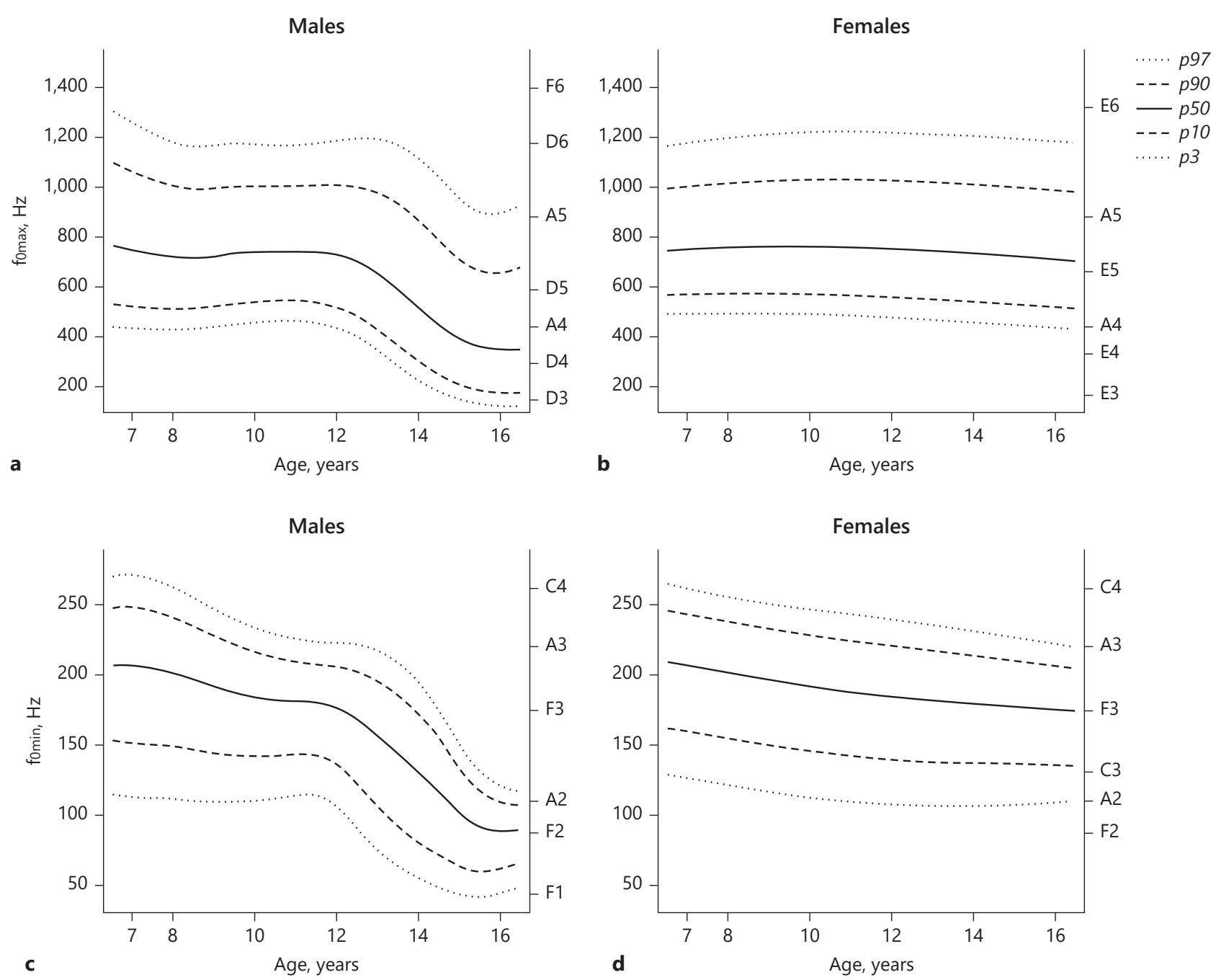

Fig. 1. Percentile curves for the variables $\mathrm{f}_{0 \max }$ for males (a), females (b), and $\mathrm{f}_{0 \min }$ for males (c) and females (d). The $y$ axes depict on the left-hand side the frequencies and on the right-hand side the corresponding scientific pitch notations.

Figure 2 shows the percentile curves for the variable $\Delta \mathrm{f}$ which is the difference between $\mathrm{f}_{0 \max }$ and $\mathrm{f}_{0 \text { min }} . \Delta \mathrm{f}$ is expressed in semitones to ensure an easy comparison. There was no significant age trend in males and females. The frequency range of around 24 semitones ( 2 octaves) stays stable over age.

As expected, the frequency lowers with age which can be attributed to adolescence for both sexes. Sex has a steady effect on the frequencies. There is a significant difference independent from age with males showing a low- er maximum and minimum frequency at all ages $(p \leq$ $0.05, f^{2}=0.57$; Table 1).

\section{SPL: Effects of Age and Sex}

In males the mean $S P L_{\max }$ of the singing voice lowers significantly over age. It shows a linear lowering of 0.05 dBA (95\% CI 0.11-0.05) per year $\left(p \leq 0.05, f^{2}=0.124\right)$. A similar development can be seen for $\mathrm{SPL}_{\min }$ with a decrease of $0.15 \mathrm{dBA}$ (95\% CI $0.23-0.06)$ per year ( $p \leq 0.05$, $\left.f^{2}=0.117\right)$. 


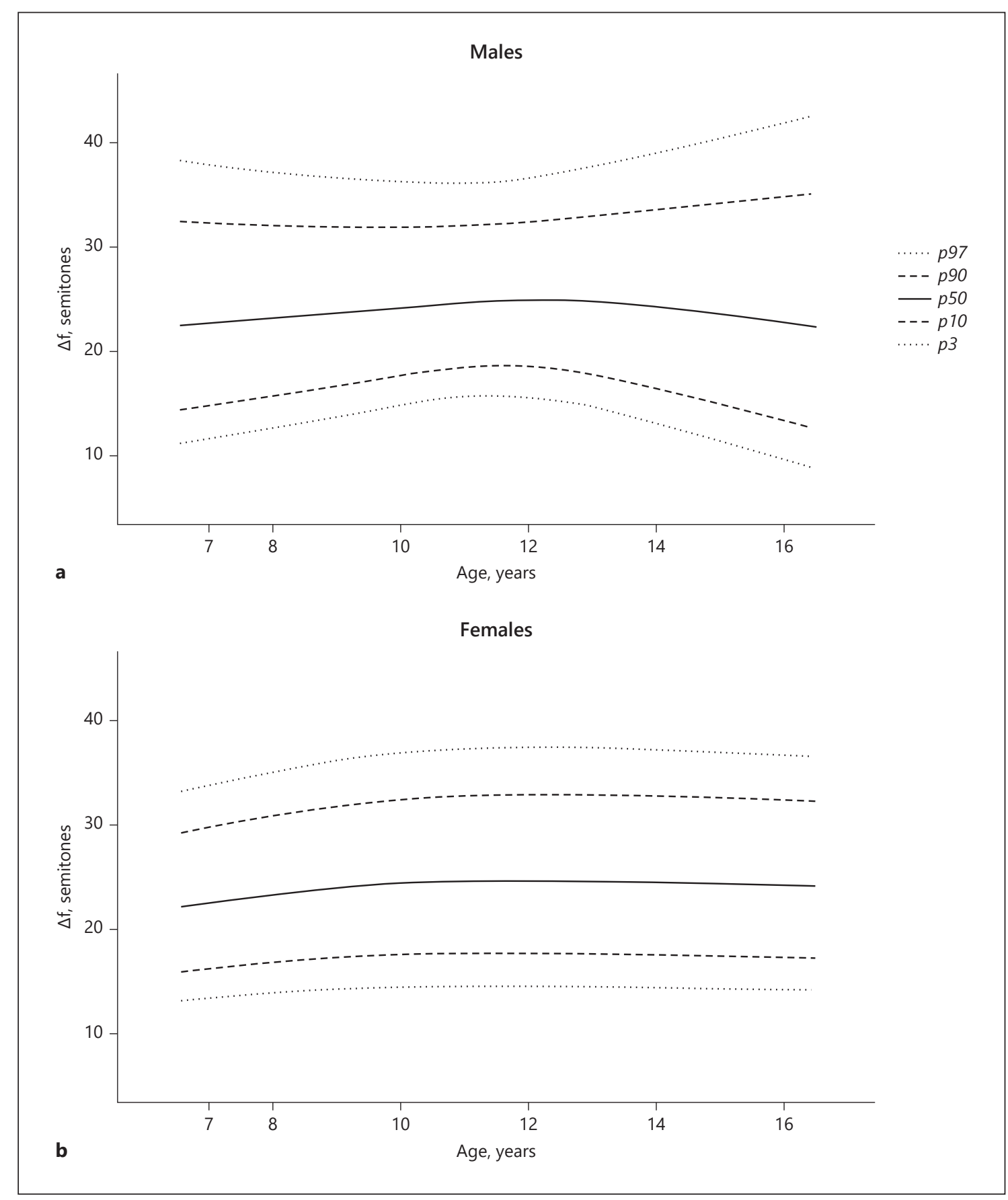

Fig. 2. The percentile curves for $\Delta \mathrm{f}$ for males (a) and females (b) depict the development of the variable over age.

In females the means of $\mathrm{SPL}_{\max }(\mathrm{b}=-0.001[95 \% \mathrm{CI}$ -0.12 to 0.12$], p=0.63)$ and $S P L_{\min }(b=-0.34(95 \% \mathrm{CI}$ -0.12 to 0.05$), p=0.44$ ) show no significant age trends.

Figure 3 shows the percentile curves of the $S P L_{\max }$ and $S P L_{\min }$ for both sexes.

\section{Maximum Phonation Time}

The variable MPT significantly increased over age. In males it increased by $0.6 \mathrm{~s}(95 \%$ CI $0.5-0.7)$ per year ( $p \leq$ $\left.0.05, f^{2}=0.42\right)$, in females it increased in a less pronounced manner by around $0.4 \mathrm{~s}(95 \%$ CI $0.3-0.4)$ per year $(p \leq$ 


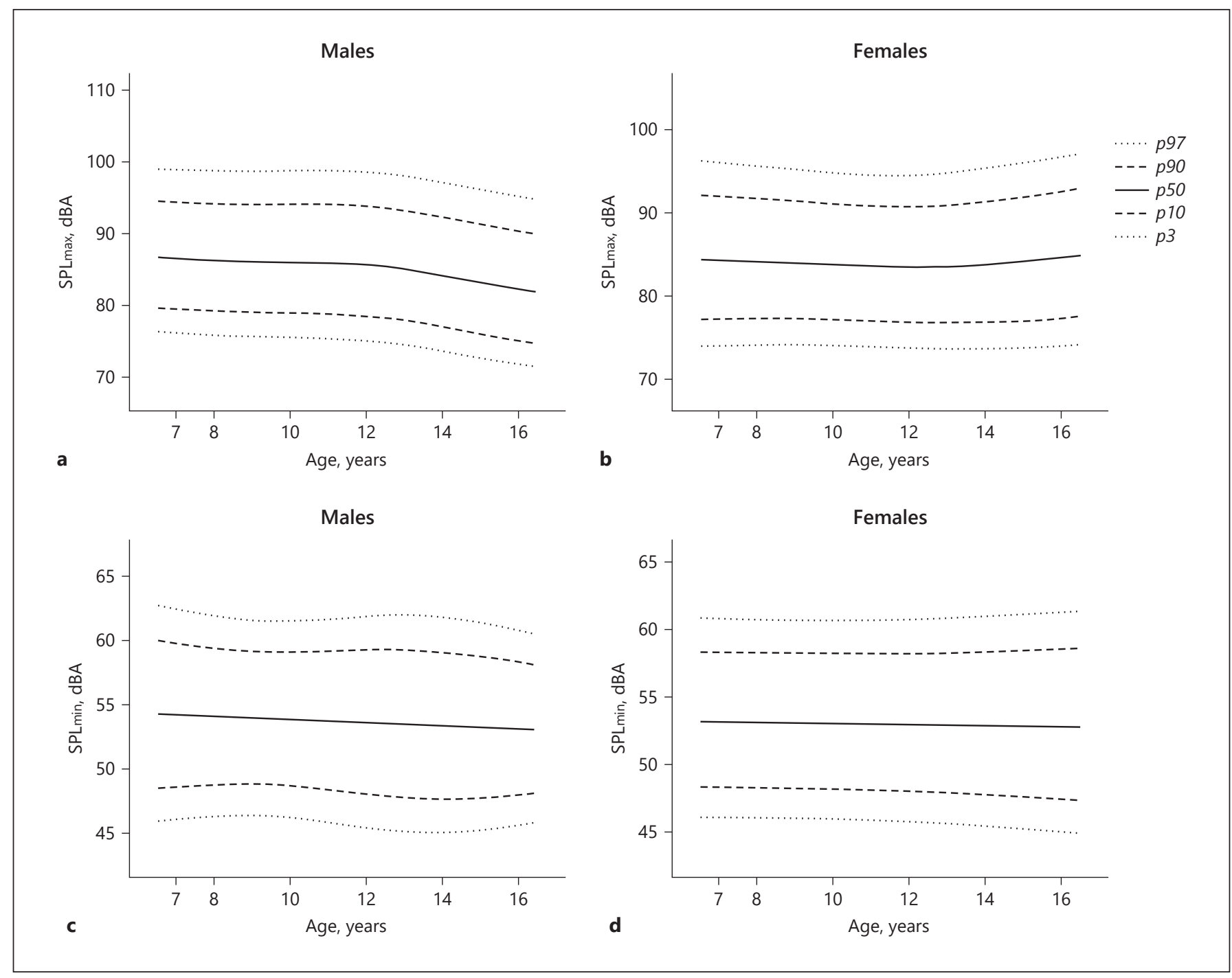

Fig. 3. Percentile curves for the variables $\mathrm{SPL}_{\max }$ for males (a), females (b), and $\mathrm{SPL}_{\min }$ for males (c) and females (d) depict the development of the variable over age.

$\left.0.05, f^{2}=0.36\right)$. We found a significant difference between the sexes with males showing significantly longer MPT than females ( $p \leq 0.05, d=0.43$; Fig. $4 \mathrm{a}$ ). In 7 -year-old children, boys were able to hold a sung tone for an average of $11.1 \mathrm{~s}$; being at the age of 16 years, they were able to hold it for around $15.9 \mathrm{~s}(p \leq 0.05, d=0.76)$. Similar effects can be seen in females showing an average of 10.7 $\mathrm{s}$ at the age of 7 compared to $14.4 \mathrm{~s}$ at the age of 16 years ( $p \leq 0.05, d=0.82)$. Figure 4 shows the respective percentile curves.

\section{Effects of Winkler Score}

The score was only available for 811 participants due to missing data. The age and sex distributions of the subsample did not differ from those of the entire sample. $27.1 \%$ of the participants belong to the lower-income families, $66.8 \%$ to the middle and $6.1 \%$ to the upper class, which resembles the distribution in Germany. For $\mathrm{f}_{0 \mathrm{~min}}$, $\mathrm{f}_{0 \max }$, and $\Delta \mathrm{f}$ there were no significant differences between the socioeconomic classes. In general, there were also no significant differences between the socioeconomic classes for $\mathrm{SPL}_{\min }$ and $\mathrm{SPL}_{\max }$. Socioeconomic status shows no influence on the variable MPT. 


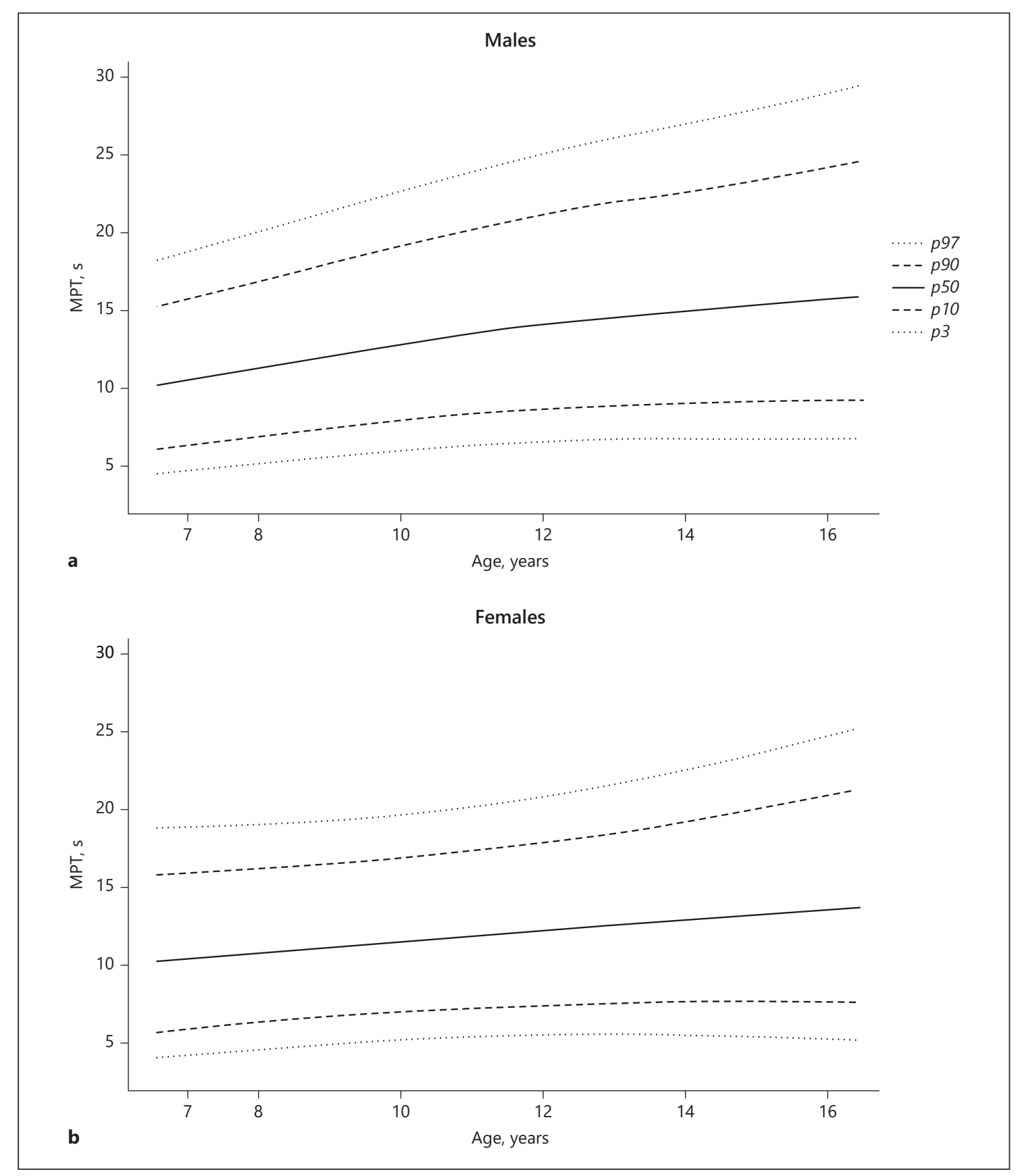

Fig. 4. The percentile curves for MPT for males (a) and females (b) depict the development of the variable over age.

\section{Discussion}

The aim of this present study was to amass normative data on the singing voice of children and adolescents. Having an unmatched large group of examinations of children aged between 7 and 16.11 gives this unique opportunity to create solid normative data.
Siupsinskiene and Lycke [30] describe that it is important for otorhinolaryngologists or phoniatricians to have a quantification of voice quality in order to be able to assess any vocal pathology. This study provides a high quality of measurements and consecutively equally valuable normative data: first, by implementing standard operating procedures as described above; second, by the 
regular supervising of the measurement process by trained phoniatricians, and third, by re-evaluating the given data in a lengthy process both visibly and audibly. This study helps to quantify the voice quality and describe a healthy voice. The percentile curves of these variables might help visualize the development and give a tool for appraising the singing voice. A comparison with previous findings might be complex, as most previous studies have used the fundamental frequency to depict the frequency of each individual by letting a subject read set texts [31-33]. Here, one goes further by describing the minimum frequency as well as the maximum frequency. It gives a much broader view on the children's singing voice. The authors also believe that a frequency range as done here shows the extent of a healthy voice of a general population of children and adolescents, following the findings of Wuyts et al. [5]. Alterations especially in the sense of a limited vocal range may be an indication of possible vocal disorders and lead to further clinical examination.

This study shows values for the minimum frequency for boys of $194.4 \mathrm{~Hz}\left(\mathrm{G}_{3}\right)$ at the age of 7 and similar ones for females of the same age $\left(202.4 \mathrm{~Hz}\left[\mathrm{Ab}_{3}\right]\right)$. These findings resemble the data of nonsinging children described by Siupsinskiene and Lycke [30]. The contrast of frequencies between the sexes is easily visible when comparing 16-year-old males with a minimum frequency of $81.9 \mathrm{~Hz}\left(\mathrm{~Gb}_{2}\right)$ and females with $175.0 \mathrm{~Hz}\left(\mathrm{~F}_{3}\right)$, the latter resembling the values found by Lycke and $\mathrm{Si}$ upsinskiene [34] for female nonsingers. A similar descent is shown with the variable maximum frequency as depicted above. The expectable effect of voice change is seen here for both males and females. The lowering of the male voice goes hand in hand with other data of the boy's voice during voice change [35-37]. It can be described by roughly one octave. This is true for the female voice as well, but not as strongly, as it only lowers by 2 semitones [38, 39]. The frequency range of about 24 semitones stays constant during ageing and is the same for females and males which is shown by other authors as well $[11,12,30]$. As $>90 \%$ of the participants are nonsingers the authors of this study deem these frequency variables as appropriate to describe voices of vocally healthy children in a population of mostly vocally inactive people.

The SPL as a parameter to describe the voice of an individual has been used by other authors as well. Their findings resemble the ones depicted in this study [8]. The minimum SPL in this study is found to be around $53 \mathrm{dBA}$ and the maximum SPL $85 \mathrm{dBA}$. Schneider-

Normative Data on Singing Voice

Parameters Using the Voice Range Profile
Stickler [40] described that a healthy voice should reach $90 \mathrm{dBA}$, even if other studies found lower values [8]. Others describe slightly higher values, even up to 97 dBA $[11,41]$. Reasons for this gap in $\mathrm{SPL}_{\max }$ could be due to the motivation of the children and the study situation where the collection of voice parameters was only one part of the many aspects and examinations of the LIFE Child Study.

MPT as an important variable to describe the healthy voice is an indicator of phonatory control [14]. In this study normative data for boys aged 7 years shows values for MPT at $11.1 \mathrm{~s}$, for females $10.7 \mathrm{~s}$ which supports findings of other authors [42]. When growing up, MPT extends for boys up to $15.9 \mathrm{~s}$ and for girls to $14.4 \mathrm{~s}$. This can also be seen in values described by Fuchs et al. [43], who stated that the MPT for boys is 3 s longer than for females. This can be explained by the physical development during puberty, as a child's growth generally increases lung capacity [44]. Some authors reckon that various morbidities tend to shorten the MPT [14, 16, 45], others discuss the influence of singing activity on the MPT. Yet, Wendler et al. [46] state that too much focus is put on the measurement of the MPT. The difference of male and female voices might also be contributed to the fact that females have a higher prevalence of posterior chinks and these are quite common during puberty [47]. The authors of this study, though, reckon that it is necessary to have reliable data on MPT. Even if not decisive to discriminate between vocally healthy and invalid children, they at least provide an auxiliary mean to support any suspicion. Further studies are needed to validate the implementation of MPT as an appraisal for a healthy voice. The percentile curves give a tool to appraise the MPT of a subject quickly and easily.

Similarly to pediatrics, these percentile curves, not only of the variable MPT, give an overview about individual results and may be used to compare them with those of other children. It thereby adds great value to the clinical routine of a phoniatrician and pediatrician as with the help of this acquired normative data one is able to find irregularities with a fast and noninvasive examination.

Socioeconomic class as an important influence for a child's health has been widely described $[48,49]$. This led to the inclusion of socioeconomic data in this study to determine whether any differences between the social class regarding the children's voice may be described. Here socioeconomic status is depicted in 3 classes as described above. Other studies describe an influence regarding vocal fold nodules [20] or communication dis- 
orders in general [3]. Those described data in another way, so any comparison might be complex. Also, there are significant confounders when associating singing voice with socioeconomic status, like the number of people living in a family or the access to health care, which were not addressed in this study $[17,50]$. The data given in this study established no significant differences between the 3 social classes regarding all the parameters. One might conclude that although social class influences other ENT- and phoniatrics-related diseases, it does not have an impact on the extent and characteristics of a child's singing voice.

\section{Limitations}

In this study the authors only took data from an area in Germany. To describe singing voice on a global scale multicentric studies need to be conducted. In addition to that, the authors did not check for a range of ethnicities or native languages so the normative data might be only suitable for Caucasian subjects due to limited representativeness [51, 52]. Further studies need to be conducted to show whether the VRP is the preferable tool for assessing vocal disorders. Musical deficits or prodigy might interfere with the diagnosis. Also, this study might be limited due to the fact that no further distinction was drawn between singers and nonsingers. The participants represent the typical distribution of singing activity in a normal population. Of course, individual conditions, like regular singing in choirs, can lead to a significant extension of the parameters. Additionally, the authors think to have a profound insight of the voice of a child one needs to assess both speaking and singing voice. Further correlations between those 2 are in need to be examined. Important information might be added in a longitudinal study as this study is a crosssectional one.

\section{Conclusion}

This present study describes reliable data of the singing voice of children with the variables $\mathrm{f}_{0 \min }, \mathrm{f}_{0 \max }, \Delta \mathrm{f}$, $\mathrm{SPL}_{\min }, \mathrm{SPL}_{\max }, \triangle \mathrm{SPL}$, and MPT for the first time. Its validity is substantiated by its unmatched high number of measurements. Using the VRP as a tool to examine a child's voice at all ages seems feasible and reliable for gathering the vocal dimension of each subject. Thus, these data allow a valid appraisal of reference values for the given variables of the singing voice of mostly vocally inactive people. The different socioeconomic backgrounds present in society seem to have no effect on vocal parameters in children without voice disorders. With this gained normative data the professional who deals with children's voices is able to distinguish between normal parameters of the singing voice and parameters that need further investigations to follow and may intervene early if necessary.

\section{Statement of Ethics}

All procedures performed in studies involving human participants are in accordance with the ethical standards of the institutional and/or national research committee and with the $1964 \mathrm{Dec}-$ laration of Helsinki and its later amendments or comparable ethical standards and under the supervision of the Ethics Committee of the University of Leipzig (Reg. No. 264-10-19042010). Informed written consent was provided by all parents and, from the age of 12 years, by the children themselves.

\section{Conflict of Interest Statement}

The authors declare that they have no conflict of interest.

\section{Funding Sources}

This publication is supported by LIFE-Leipzig Research Center for Civilization Diseases, University of Leipzig. LIFE is funded by means of the European Union, by means of the European Social Fund (ESF), by the European Regional Development Fund (ERDF), and by means of the Free State of Saxony within the framework of the excellence initiative. The Integrated Research and Treatment Center Adiposity Diseases is funded by the German Federal Ministry of Education and Research (grant 01EO1501). XION Medical (Berlin, Germany) kindly provided the technical equipment and software for conducting voice measurements.

\section{Author Contributions}

T.B., T.D., M.F., and W.K. conceived of the presented idea. T.B., M.F., and W.K. conceived and planned the experiments. The LIFE Child Research Center carried out the experiments. T.D. performed the computations. C.E., T. Peschel, T. Poulain, and M.V. verified the analytical methods. T.D. took the lead in writing the paper. All authors provided critical feedback and helped shape the research, analysis, and paper. 


\section{References}

1 Connor NP, Cohen SB, Theis SM, Thibeault SL, Heatley DG, Bless DM. Attitudes of children with dysphonia. J Voice. 2008 Mar; 22(2):197-209.

2 Infusino SA, Diercks GR, Rogers DJ, Garcia J, Ojha S, Maurer R, et al. Establishment of a normative cepstral pediatric acoustic database. JAMA Otolaryngol Head Neck Surg. 2015 Apr;141(4):358-63.

3 Ruben RJ. Valedictory-why pediatric otorhinolaryngology is important. Int J Pediatr Otorhinolaryngol. 2003 Dec;67(suppl 1):S53-61.

4 Carding PN, Roulstone S, Northstone K; ALSPAC Study Team. The prevalence of childhood dysphonia: a cross-sectional study. Voice. 2006 Dec;20(4):623-30.

5 Wuyts FL, Heylen L, Mertens F, Du Caju M, Rooman R, Van de Heyning PH, et al. Effects of age, sex, and disorder on voice range profile characteristics of 230 children. Ann Otol Rhinol Laryngol. 2003 Jun;112(6):540-8.

6 Kallvik E, Lindström E, Holmqvist S, Lindman J, Simberg S. Prevalence of hoarseness in school-aged children. J Voice. 2015 Mar; 29(2):260.e1-19.

7 Simberg S, Sala E, Laine A, Rönnemaa AM. A fast and easy screening method for voice disorders among teacher students. Logoped Phoniatr Vocol. 2001;26(1):10-6.

8 Böhme G, Stuchlik G. Voice profiles and standard voice profile of untrained children. J Voice. 1995 Sep;9(3):304-7.

9 Pedersen MF. A longitudinal pilot study on phonetograms/voice profiles in pre-pubertal choir boys. Clin Otolaryngol Allied Sci. 1993 Dec;18(6):488-91.

10 Titze IR. The G. Paul Moore Lecture. Toward standards in acoustic analysis of voice. J Voice. 1994 Mar;8(1):1-7.

11 Schneider B, Zumtobel M, Prettenhofer W, Aichstill B, Jocher W. Normative voice range profiles in vocally trained and untrained children aged between 7 and 10 years. J Voice. 2010 Mar;24(2):153-60.

12 McAllister A, Sederholm E, Sundberg J, Gramming P. Relations between voice range profiles and physiological and perceptual voice characteristics in ten-year-old children. J Voice. 1994 Sep;8(3):230-9.

13 Hirano M, McCormick KR. Clinical Examination of Voice by Minoru Hirano. J Acoust Soc Am. 1986 Oct;80(4):1273.

14 Hillel AD, Yorkston K, Miller RM. Using phonation time to estimate vital capacity in amyotrophic lateral sclerosis. Arch Phys Med Rehabil. 1989 Aug;70(8):618-20.

15 Ma EP, Yiu EM. Multiparametric evaluation of dysphonic severity. J Voice. 2006 Sep;20(3): 380-90.

16 Prathanee B, Sae Soew P, Pongjanyakul A, Sae-Heng S. Time and frequency of maximum phonation of normal Thai children in Khon Kaen. J Multilingual Commun Disord. 2003 Jan;1(1):71-8.
17 Bradley RH, Corwyn RF. Socioeconomic status and child development. Annu Rev Psychol. 2002;53(1):371-99.

18 Qi CH, Kaiser AP. Problem behaviors of lowincome children with language delays: an observation study. J Speech Lang Hear Res. 2004 Jun;47(3):595-609.

19 Poulain T, Fuchs M, Vogel M, Jurkutat A, Hiemisch A, Kiess W, et al. Associations of Speaking-Voice Parameters With Personality and Behavior in School-Aged Children. J Voice. 2020 May;34(3):485.e23-31.

20 Smillie I, McManus K, Cohen W, Lawson E, Wynne DM. The paediatric voice clinic. Arch Dis Child. 2014 Oct;99(10):912-5.

21 Poulain T, Baber R, Vogel M, Pietzner D, Kirsten T, Jurkutat A, et al.; LIFE Child study team. The LIFE Child study: a populationbased perinatal and pediatric cohort in Germany. Eur J Epidemiol. 2017 Feb;32(2):14558.

22 Quante M, Hesse M, Döhnert M, Fuchs M, Hirsch C, Sergeyev E, et al.; LIFE Child Study Investigators. The LIFE child study: a life course approach to disease and health. BMC Public Health. 2012 Nov;12(1):1021.

23 Berger T, Peschel T, Vogel M, Pietzner D, Poulain T, Jurkutat A, et al. Speaking Voice in Children and Adolescents: Normative Data and Associations with BMI, Tanner Stage, and Singing Activity. J Voice. 2019 Jul;33(4): 580.e21-30.

24 Schutte HK, Seidner W. Recommendation by the Union of European Phoniatricians (UEP): standardizing voice area measurement/phonetography. Folia Phoniatr (Basel). 1983; 35(6):286-8.

25 Lampert T, Müters S, Stolzenberg H, Kroll LE. Messung des sozioökonomischen Status in der KiGGS-Studie. Bundesgesundheitsbl. 2014;57:762-770.

26 Winkler J, Stolzenberg H. Adjustierung des Sozialen-Schicht-Index für die Anwendung im Kinder-und Jugendgesundheitssurvey (KiGGS). Wismarer Diskussionspapiere; 2009.

27 Fuchs M, Meuret S, Geister D, Pfohl W, Thiel S, Dietz A, et al. Empirical criteria for establishing a classification of singing activity in children and adolescents. J Voice. 2008 Nov; 22(6):649-57.

28 Rigby RA, Stasinopoulos DM. Generalized additive models for location, scale and shape. J R Stat Soc Ser C Appl Stat. 2005 Jun;54(3): $507-54$.

29 Smoothing reference centile curves: The lms method and penalized likelihood - Cole 1992 - Statistics in Medicine - Wiley Online Library. Available from: https://onlinelibrary. wiley.com/doi/abs/10.1002/sim.4780111005 (Accessed August 13, 2019).
30 Siupsinskiene N, Lycke H. Effects of vocal training on singing and speaking voice characteristics in vocally healthy adults and children based on choral and nonchoral data. J Voice. 2011 Jul;25(4):e177-89.

31 Guzman M, Muñoz D, Vivero M, Marín N, Ramírez M, Rivera MT, et al. Acoustic markers to differentiate gender in prepubescent children's speaking and singing voice. Int J Pediatr Otorhinolaryngol. 2014 Oct;78(10): 1592-8.

32 Sorenson DN. A fundamental frequency investigation of children ages $6-10$ years old. J Commun Disord. 1989 Apr;22(2):115-23.

33 Lee S, Potamianos A, Narayanan S. Acoustics of children's speech: developmental changes of temporal and spectral parameters. J Acoust Soc Am. 1999 Mar;105(3):1455-68.

34 Lycke H, Siupsinskiene N. Voice Range Profiles of Singing Students: The Effects of Training Duration and Institution. Folia Phoniatr Logop. 2016;68(2):53-9.

35 Hollien $\mathrm{H}$. On pubescent voice change in males. J Voice. 2012 Mar;26(2):e29-40.

36 Hollien H, Green R, Massey K. Longitudinal research on adolescent voice change in males. J Acoust Soc Am. 1994 Nov;96(5 Pt 1):264654.

37 Naidr J, Zbořil M, Ševčík K. Die pubertalen Veränderungen der Stimme bei Jungen im Verlauf von 5 Jahren. Folia Phoniatr Logop. 1965;17(1):1-18.

38 Harries ML, Walker JM, Williams DM, Hawkins S, Hughes IA. Changes in the male voice at puberty. Arch Dis Child. 1997 Nov; 77(5):445-7.

39 Spiegel JR, Sataloff RT, Emerich KA. The young adult voice. J Voice. 1997 Jun;11(2): $138-43$.

40 Schneider-Stickler B. Stimmstörungen im Kindesalter. HNO. 2012 Jul;60(7):590-4.

41 Brockmann-Bauser M, Beyer D, Bohlender JE. Reliable acoustic measurements in children between 5;0 and 9;11 years: Gender, age, height and weight effects on fundamental frequency, jitter and shimmer in phonations without and with controlled voice SPL. Int J Pediatr Otorhinolaryngol. 2015 Dec;79(12): 2035-42.

42 Fuchs M, Heide S, Hentschel B, Gelbrich G, Makuch A, Thiel S, et al. Stimmleistungsparameter bei Kindern und JugendlichenVocal efficiency parameters in children and adolescents. HNO. 2006 Dec;54(12):971-80.

43 Fuchs M, Meuret S, Thiel S, Täschner R, Dietz A, Gelbrich G. Influence of singing activity, age, and sex on voice performance parameters, on subjects' perception and use of their voice in childhood and adolescence. J Voice. 2009 Mar;23(2):182-9.

44 Finnegan DE. Maximum phonation time for children with normal voices. Folia Phoniatr (Basel). 1985;37(5-6):209-15.
Normative Data on Singing Voice

Parameters Using the Voice Range Profile
Folia Phoniatr Logop 2021;73:565-576

DOI: $10.1159 / 000513521$ 
45 Harden JR, Looney NA. Duration of sustained phonation in kindergarten children. Int J Pediatr Otorhinolaryngol. 1984 Mar; 7(1):11-9.

46 Wendler J, Seidner W, Eysholdt U. Lehrbuch der Phoniatrie und Padaudiologie, 3rd ed. Logoped Phoniatr Vocol. 1998 Jan;23(1):446.

47 Chandran S, Hanna J, Lurie D, Sataloff RT. Differences between flexible and rigid endoscopy in assessing the posterior glottic chink. J Voice. 2011 Sep;25(5):591-5.
48 Holstein BE, Jørgensen SE, Due P, Damsgaard MT, Rasmussen M. Short report: persistent social inequality in poor self-rated health among adolescents in Denmark 19912014. Eur J Public Health. 2018 Dec;28(6): 1114-6.

49 Adler NE, Glymour MM, Fielding J. Addressing Social Determinants of Health and Health Inequalities. JAMA. 2016 Oct;316(16):16412.
50 Espenshade TJ, Kamenske G, Turchi BA. Family size and economic welfare. Fam Plann Perspect. 1983 Nov-Dec;15(6):289-94.

51 Andrianopoulos AV, Darrow KN, Chen J. Multimodal standardization of voice among four multicultural populations: fundamental frequency and spectral characteristics. J Voice. 2001 Jun;15(2):194-219.

52 Xue SA, Hao JG. Normative standards for vocal tract dimensions by race as measured by acoustic pharyngometry. J Voice. 2006 Sep; 20(3):391-400 